\title{
Imaging Response Inhibition in a Stop-Signal Task: Neural Correlates Independent of Signal Monitoring and Post-Response Processing
}

\author{
Chiang-shan Ray Li, ${ }^{1}$ Cong Huang, ${ }^{1,2}$ R. Todd Constable, ${ }^{3}$ and Rajita Sinha ${ }^{1}$ \\ Departments of ${ }^{2}$ Psychiatry, ${ }^{2}$ Statistics, and ${ }^{3}$ Diagnostic Radiology and Neurosurgery, and Magnetic Resonance Research Center, Yale University, New \\ Haven, Connecticut 06519
}

\begin{abstract}
Execution of higher cortical functions requires inhibitory control to restrain habitual responses and meet changing task demands. We used functional magnetic resonance imaging to show the neural correlates of response inhibition during a stop-signal task. The task has a frequent "go" stimulus to set up a pre-potent response tendency and a less frequent "stop" signal for subjects to withhold their response. We contrasted brain activation between successful and failed inhibition for individual subjects and compared groups of subjects with short and long stop-signal reaction times. The two groups of subjects did not differ in their inhibition failure rates or the extent of signal monitoring, error monitoring, or task-associated frustration ratings. The results showed that short stop-signal reaction time or more efficient response inhibition was associated with greater activation in the superior medial and precentral frontal cortices. Moreover, activation of these inhibitory motor areas correlated negatively with stop-signal reaction time. These brain regions may represent the neural substrata of response inhibition independent of other cognitive and affective functions.
\end{abstract}

Key words: fMRI; go/nogo; inhibitory motor area; impulsivity; cognitive; executive; prefrontal

\section{Introduction}

The ability to suppress a pre-potent response is an important executive control function. Response inhibition allows appropriate responses to meet complicated task demands and adaptation to changing environments. One of the most common measures of response inhibition is the go/no-go or stop-signal task. In these behavioral tasks, the dominant or more frequent stimulus constitutes a go signal requiring the subjects to respond within a time window and therefore sets up a pre-potent response tendency. The other, less frequent no-go or stop signal instructs the subjects to refrain from making the response. Previous studies have shown that patients with a variety of psychiatric and neurological conditions, including attention deficit hyperactivity disorder, have impaired response inhibition during such tasks (Aron and Poldrack, 2005). The neural correlates of response inhibition are thus relevant to the neuropathology of these disorders as well as to cognitive functions more broadly.

Functional magnetic resonance imaging (fMRI) has been widely used to examine response inhibition. Previous fMRI stud-

Received July 9, 2005; revised 0ct. 25, 2005; accepted Nov. 2, 2005.

This work was supported by the Yale Interdisciplinary Women's Health Research Scholar Program on Women and Drug Abuse (Building Interdisciplinary Research Careers in Women's Health; K12-DA14038), the National Institutes of Health (NIH) Office of Research on Women's Health, and National Institute on Drug Abuse-NIH Grants P50DA16556 (R.S.) and K02-DA17232 (R.S.) to Yale University. We thank Drs. Kathleen Hansen, Jamie Mazer, and Pawel Skudlarski for their valuable discussions and Dr. Tom Kosten for his most helpful comments on this manuscript.

Correspondence should be addressed to Dr. Chiang-shan Ray Li, Assistant Professor, Connecticut Mental Health Center, Room S103, Department of Psychiatry, Yale University School of Medicine, 34 Park Street, New Haven, CT 06519. E-mail: chiang-shan.li@yale.edu.

DOI:10.1523/JNEUROSCI.3741-05.2006

Copyright $\odot 2006$ Society for Neuroscience $\quad$ 0270-6474/06/260186-07\$15.00/0 ies have compared brain activation during blocks of go and mixed go/stop trials. Although such contrasts may reveal the activation associated with response inhibition, they may also reflect differences associated with other cognitive and affective processes that are unequally represented between these blocks. For instance, the go block contains more motor responses, whereas the mixed go/ stop block contains higher task demand with greater signal and performance monitoring, greater oddball attention effect, and more emotional frustration because errors are made more frequently. With these potential confounds, previous studies have localized a wide array of brain regions including the prefrontal and cingulate cortices, basal ganglia, and cerebellum, showing greater activation in the mixed than in the go blocks (Menon et al., 2001; Rubia et al., 2001). For instance, Menon et al. (2001) found greater activation during the mixed go/no-go than the go epochs in bilateral dorsolateral prefrontal, inferior frontal, premotor, lingual, and inferior parietal gyri, bilateral caudate nuclei, and the right anterior cingulate cortex. These regional activations could reflect higher demand for working memory as well as attentional and affective processes during mixed blocks, because these blocks require more complicated sensorimotor mapping, task switching, error monitoring (EM), and other post-response processing. With go and stop trials intermixed, event-related fMRI studies circumvented most of these confounding variables (Konishi et al., 1998; Garavan et al., 1999; Liddle et al., 2001; Durston et al., 2002). In particular, in a stop-signal task in which the time interval between the stop and go signal tracked a subject's performance, one could achieve successful inhibitions in approximately one-half of the stop trials (Rubia et al., 2003, 
2005). By contrasting successful and unsuccessful inhibitions, these investigators identified the right inferior frontal cortex (IFC) as specifically mediating response inhibition. However, although this contrast controlled for certain pre-response differences between successful and failed inhibition, it did not control for differences in signal monitoring and post-response processing. Successful performance in the stop-signal task requires sustained attention and constant monitoring for the stop signal. Lapses in attention or failures in monitoring cause inhibition failures (e.g., when one responds to the go signal, assuming no stop signal will follow). Therefore, by contrasting successful and failed inhibition, one might simply be isolating activations related to such signal monitoring process. Moreover, compared with inhibition successes, inhibition failures incur emotional frustration and EM, which prompted adjustments in response strategy. Such differences in cognitive and affective processes may have contributed to the regional brain activations attributed previously to response inhibition.

The current study attempted to address these confounds by proposing a new method to isolate the neural correlates of response inhibition. We used a tracking stop-signal task and computed the stop-signal reaction time (SSRT) as an index of the response inhibition function for each individual subject (Logan, 1994). The SSRT estimated the time required for the stop signal to be processed so a response could be withheld, according to a horse race model. We assumed that a shorter SSRT would result from greater activation of brain regions that mediated response inhibition. Therefore, by contrasting groups of subjects with short and long SSRTs, we could potentially isolate the neural correlates of response inhibition. Importantly, by comparing these two groups of subjects that showed no differences in their inhibition failure rate, we can control the confounding effect of signal monitoring. This contrast also allowed the evaluation of post-response processes as covariates.

\section{Materials and Methods}

Subjects and behavioral task. Twenty-four adult healthy subjects (18 males and 6 females, 22-42 years of age, all right-handed and using the right hand to respond) were paid to participate in the study. All subjects signed a written consent after details of the study were explained, in accordance with institute guidelines and procedures approved by the Yale Human Investigation Committee. We used a simple reaction time (RT) task in this stop-signal paradigm. There were two trial types: "go" and "stop." A small dot appeared on the screen to engage attention and eye fixation (although eye position was not monitored) at the beginning of a go trial. After a randomized time interval (fore-period; between 1 and $5 \mathrm{~s})$, the dot turned into a circle, which subtended $\sim 2^{\circ}$ of visual angle. The circle served as an imperative stimulus, and the subjects were instructed to quickly press a button at the go signal but not before. The circle vanished at button press or after $1 \mathrm{~s}$ had elapsed, whichever came first, and the trial terminated. A premature button press before the appearance of the circle also terminated the trial. Three quarters of all trials were go trials. In a stop trial, an additional " $\mathrm{X}$," the stop signal, appeared after the go signal. The subjects were told to withhold button press after seeing the stop signal. Likewise, a trial terminated at button press or when $1 \mathrm{~s}$ had elapsed since the appearance of the stop signal. Clearly, it would be easier for the subject to withhold the response if the stop signal appeared immediately or early after the go signal, and the reverse applied if the time interval between the stop and the go signals [or the stop-signal delay (SSD)] was extended. The SSD started at $200 \mathrm{~ms}$ and varied from one stop trial to the next according to a staircase procedure: if the subject succeeded in withholding the response, the SSD increased by $64 \mathrm{~ms}$; conversely, if they failed, the SSD decreased by $64 \mathrm{~ms}$. With the staircase procedure, a "critical" SSD could be computed that represented the time delay required for the subject to succeed in withholding a response in the stop trials half of the time (Levitt, 1970). The SSRT was then estimated for each individual subject by subtracting the critical SSD from the mean go trial RT. The stop trials constituted the remaining one-quarter of the trials. There was an intertrial interval of $2 \mathrm{~s}$. Subjects were instructed to respond to the go signal quickly while keeping in mind that a stop signal could come up in a small number of trials. Before the fMRI study, each subject had $\sim 20$ practice trials outside the scanner. Each subject completed four 10 min runs of the task with the SSD updated manually across runs. Depending on the actual stimulus timing (trial varied in foreperiod duration) and speed of response, the total number of trials varied slightly across subjects in an experiment. With the staircase procedure, we anticipated that the subjects would succeed in withholding their response in $\sim 50 \%$ of the stop trials.

After they completed the third block of task, subjects were asked to rate their frustration and stress level associated with the task on a Likert scale from 1 to 10 , with 10 being the most frustrating experience they have ever had before. We also computed a behavioral index of EM. It is known that in a RT task, the RT of a correct response is prolonged after an error, compared with other correct responses, and this prolonged RT is thought to reflect cognitive processes involved in EM (Rabbit, 1966). We thus computed the RT difference between the go trials that followed an unsuccessful inhibition and those that followed another go trial and termed this RT difference an EM effect. Both frustration rating and EM effect reflected post-response processing.

Imaging protocol. Conventional $\mathrm{T}_{1}$-weighted spin-echo sagittal anatomical images were acquired for slice localization using a $3 \mathrm{~T}$ scanner (Trio; Siemens AG, Erlangen, Germany). Anatomical images of the functional slice locations were next obtained with spin-echo imaging in the axial plane parallel to the anterior and posterior commissure (AC-PC) line with the following: repetition time (TR), $300 \mathrm{~ms}$; echo time (TE), 2.5 $\mathrm{ms}$; bandwidth, $300 \mathrm{~Hz} /$ pixel; flip angle, $60^{\circ}$; field of view, $220 \times 220 \mathrm{~mm}$; matrix, $256 \times 256$; 32 slices with a slice thickness of $4 \mathrm{~mm}$ and no gap. Functional blood oxygen level-dependent (BOLD) signals were then acquired with a single-shot gradient-echo echoplanar imaging (EPI) sequence. Thirty-two axial slices parallel to the AC-PC line covering the entire brain were acquired with the following: TR, $2000 \mathrm{~ms}$; TE, $25 \mathrm{~ms}$; bandwidth, $2004 \mathrm{~Hz} /$ pixel; flip angle, $85^{\circ}$; field of view, $220 \times 220 \mathrm{~mm}$; matrix, $64 \times 64 ; 32$ slices with a slice thickness of $4 \mathrm{~mm}$ and no gap. Three hundred images were acquired in each run for a total of four runs.

Data analysis and statistics. Data were analyzed with Statistical Parametric Mapping version 2 (Welcome Department of Imaging Neuroscience, University College London, London, UK). Images from the first five TRs at the beginning of each trial were discarded to enable the signal to achieve steady-state equilibrium between radio-frequency pulsing and relaxation. Images of each individual subject were first corrected for slice timing and realigned (motion corrected). A mean functional image volume was constructed for each subject for each run from the realigned image volumes. These mean images were normalized to a Montreal Neurological Institute (MNI) EPI template with affine registration, followed by nonlinear transformation (Friston et al., 1995a; Ashburner and Friston, 1999). The normalization parameters determined for the mean functional volume were then applied to the corresponding functional image volumes for each subject. Finally, images were smoothed with a Gaussian kernel of $10 \mathrm{~mm}$ at full-width at half-maximum. The data were high-pass filtered (1/128 Hz cutoff) to remove low-frequency signal drifts.

Four types of trial outcomes were distinguished: successful go trial (type 1), failed go trial (type 2), successful stop trial (type 3), and failed stop trial (type 4). A statistical analytical design was constructed for each individual subject, using the general linear model with the onsets of go signal in each of these trial types convolved with a canonical hemodynamic response function and with the temporal derivative of the canonical hemodynamic response function and entered as regressors in the model (Friston et al., 1995b). Because each successful go trial was associated with a different RT, we entered a column of type 1 trial onset parametrically modulated by its corresponding RT as a regressor in the model. Likewise, because the stop (type 3 and type 4) trials came with different SSDs, we entered columns of type 3 and type 4 trial onsets parametrically modulated by SSDs in the model. Realignment parame- 


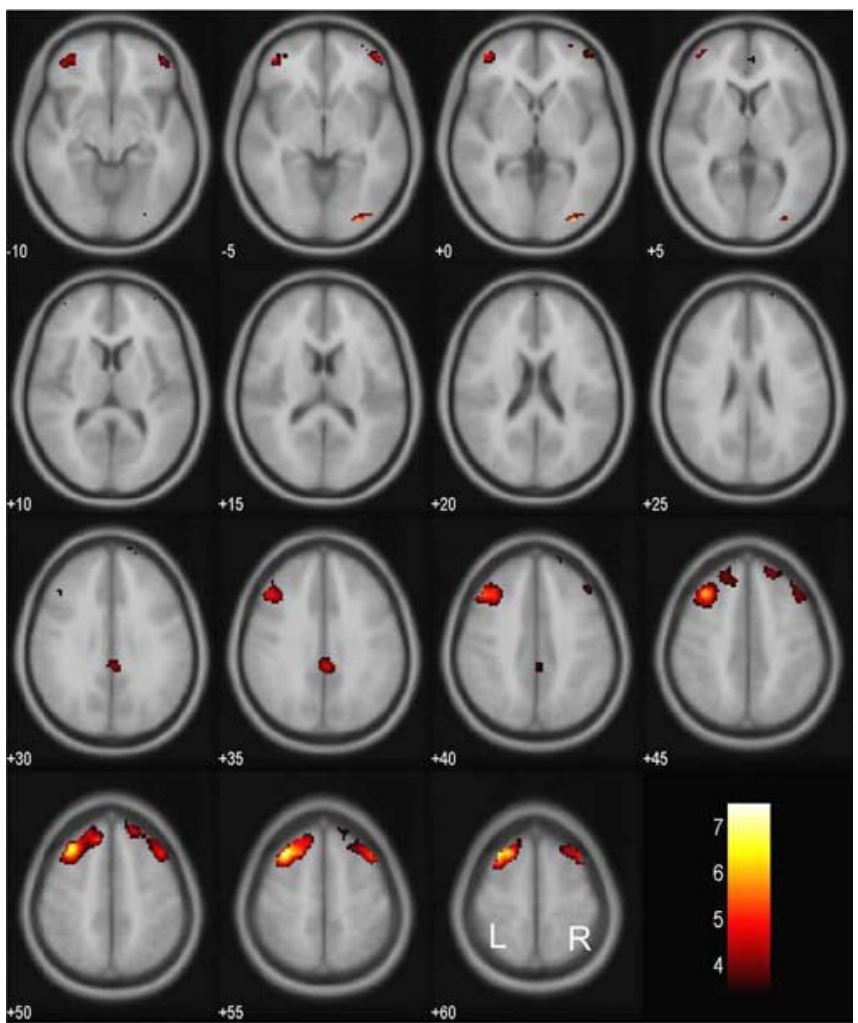

Figure 1. Brain regions showing more activation in successful compared with failed inhibitions. BOLD contrasts are superimposed on a T1 structural image in axial sections from $z=-10$ to $z=60$. The adjacent sections are $5 \mathrm{~mm}$ apart. The color bar represents voxel $T$ value. L, Left; $\mathrm{R}$, right.

Table 1. Brain regions more activated in successful compared with failed inhibitions

\begin{tabular}{|c|c|c|c|c|c|c|}
\hline \multirow{2}{*}{$\begin{array}{l}\text { Cluster size } \\
\text { (voxels) }\end{array}$} & \multirow{2}{*}{$\begin{array}{l}\text { Voxel Z } \\
\text { value }\end{array}$} & \multicolumn{3}{|c|}{ Talairach coordinates (mm) } & \multirow[b]{2}{*}{ Side } & \multirow[b]{2}{*}{ Identified region and $B A$} \\
\hline & & $x$ & $y$ & $Z$ & & \\
\hline 216 & 5.29 & -32 & 20 & 47 & $\mathrm{~L}$ & Middle frontal G, BA 8 \\
\hline 24 & 5.25 & 27 & -89 & -8 & $\mathrm{R}$ & Inferior occipital G, BA 18 \\
\hline \multirow[t]{2}{*}{33} & 3.30 & 27 & 39 & -9 & $\mathrm{R}$ & Inferior frontal G, BA 11 \\
\hline & 3.21 & 24 & 55 & -1 & $\mathrm{R}$ & Middle frontal G, BA 10 \\
\hline \multirow[t]{2}{*}{135} & 4.23 & 34 & 12 & 50 & $\mathrm{R}$ & Middle frontal G, BA 6 \\
\hline & 3.23 & 17 & 51 & 38 & $\mathrm{R}$ & Superior frontal G, BA 8 \\
\hline \multirow[t]{2}{*}{41} & 4.17 & -40 & 47 & 2 & $\mathrm{~L}$ & Inferior frontal G, BA 10 \\
\hline & 4.06 & -32 & 43 & -9 & $\mathrm{~L}$ & Middle frontal G, BA 11 \\
\hline 27 & 3.91 & 3 & -38 & 26 & $\mathrm{R}$ & Cingulate $\mathrm{G}, \mathrm{BA} 31$ \\
\hline
\end{tabular}

Statistical threshold: $p=0.05$, FDR corrected; extent, 10 voxels. G, Gyrus; L, left; R, right.

ters in all six dimensions were also entered in the model. Serial autocorrelation caused by aliased cardiovascular and respiratory effects was corrected by a first-degree autoregressive or $\mathrm{AR}(1)$ model. The general linear model estimated the component of variance that could be explained by each of the regressors.

In the first-level analysis, we constructed for each individual subject one statistical contrast: successful minus failed stop trials. This contrast allowed us to evaluate brain regions that were activated or deactivated during successful stop trials compared with failed stop trials. The con or contrast (difference in $\beta$ ) images of the first-level analysis were then used for the second-level group statistics (random-effect analysis). Conversion of the MNI to the Talairach coordinates (Talairach and Tournoux, 1988) was accomplished using a linear algorithm (Brett et al., 2002a) (http://www.mrc-cbu.cam.ac.uk/Imaging/Common/mnispace.shtml), and Brodmann's areas (BA) were identified using the Talairach Daemon (Lancaster et al., 1997) (http://ric.uthscsa.edu/projects/talairachdaemon. html). In region-of-interest (ROI) analysis, we used MarsBaR (Brett et al. 2002b) (http://marsbar.sourceforge.net/) to derive for each individual subject the effect size of activity change in successful versus failed stop trials for the ROIs. This difference in regional activation was then used to correlate with SSRT, EM effect, and frustration ratings across subjects.

\section{Results}

We compared brain activations between successful and failed stop trials for all individual subjects. The results from a onesample $t$ test of all 24 subjects showed that, at a height threshold of $p=0.05$, corrected for false discovery rate (FDR) (Genovese et al., 2002) and an extent threshold of 10 voxels, successful inhibition was associated with greater bihemispheric activation of multiple cortical areas (Fig. 1). These areas included the left middle frontal gyrus, right inferior occipital gyrus, right inferior and middle frontal gyri, a different cluster of right middle and superior frontal gyri, left inferior and middle frontal gyri, and right cingulate gyrus. These areas are summarized in Table 1. Conversely, compared with successful inhibition, failed inhibition was associated with greater activation in other brain areas including the following (Fig. 2): the right and left lingual gyri, left precentral gyrus, left medial frontal gyrus, and left pulvinar. These areas are summarized in Table 2.

To isolate the neural correlates associated with response inhibition, we used a median split to compare those 12 subjects with shorter SSRTs with the other 12 subjects with longer SSRTs (mean \pm SD; $180 \pm 20$ vs $249 \pm 22 \mathrm{~ms} ; p<0.0001$; two-sample $t$ test). These two groups of subjects did not differ in their general demographics including age $(29.1 \pm 4.6$ vs $29.0 \pm 3.8$ years $)$, education $(17.7 \pm 4.4$ vs $18.0 \pm 2.2$ years $)$, and gender composition (each with 9 males and 3 females), in their task-related frustration rating (mean rank, 12.25 vs $12.75 ; p=0.86$; Mann-Whitney $U$ test), or in their general performance (short SSRT vs long SSRT): go trial RT, $600 \pm 104$ versus $558 \pm 133 \mathrm{~ms}$; go trial success rate, $95.8 \pm 3.5$ versus $96.6 \pm 3.2 \%$; stop trial success rate, $51.5 \pm 1.8$ versus $50.5 \pm 2.9 \%$ (all values are mean $\pm \mathrm{SD}$; all $p>$ $0.4)$. The comparison showed greater activation in the left superior frontal gyrus $(x=-4, y=32, z=51$, voxel $Z=4.91$; BA 8) and left precentral gyrus $(x=-36, y=8, z=39$, voxel $Z=4.05$; BA 9) at a threshold of $p=0.05$, FDR corrected. As the threshold was relaxed ( $p=0.001$, uncorrected; extent, 10 voxels), additional activation was found in the left anterior cingulate gyrus $(x=-8, y=35, z=19$, voxel $Z=3.46$; BA 32). Figure 3 highlights these regional activations, and Table 3 summarizes these areas. No brain regions showed greater activation in the long compared with the short SSRT group at this statistical threshold. However, the short SSRT group demonstrated a trend in having greater EM than the long SSRT group (mean $\pm \mathrm{SD}$; $49 \pm 33$ vs $23 \pm 31 \mathrm{~ms} ; p=0.066$; two-tailed, two-sample $t$ test). In other words, subjects in the short SSRT group appeared to demonstrate greater adjustment in go trial RT after making an error in a stop trial compared with the long SSRT group. To account for this EM difference between groups, we compared the short and long SSRT groups including EM as a covariate. The results of this covariance analysis showed greater activation in the same brain regions as the analysis without this covariate, and again, no brain areas demonstrated more activation in the long than in the short SSRT group. The brain regions showing greater activation in the short SSRT group were as follows $(p=0.001$, uncorrected; extent, 10 voxels): left superior frontal gyrus ( $x=$ $-4, y=32, z=51$, voxel $Z=4.52,51$ voxels; BA 8), left precentral gyrus $(x=-36, y=8, z=35$, voxel $Z=3.60,22$ voxels; BA 9), left medial frontal gyrus $(x=-4, y=59, z=20$, voxel $Z=$ 
$3.49,12$ voxels; BA 10), and left anterior cingulate $(x=-8, y=$ $39, z=16$, voxel $Z=3.42,12$ voxels; BA 32).

In ROI analysis, we defined two functional ROIs: one combining the superior frontal $(x=-4, y=32, z=51$, peak voxel $Z=$ $4.91,55$ voxels; cluster $p=0.008)$ and precentral $(x=-36, y=$ $8, z=39$, peak voxel $Z=4.05,35$ voxels; cluster $p=0.027$ ) clusters (see Discussion) and the other from the anterior cingulate cluster $(x=-8, y=35, z=19$, peak voxel $Z=3.46,17$ voxels; cluster $p=0.108)$, identified with a statistical threshold of $p=0.001$, uncorrected. We tested a more stringent hypothesis that activation in these regions linearly correlated with SSRT. Activation in the superior frontal/precentral cluster correlated negatively with SSRT (Pearson $r=-0.651$; $p<0.0006$ ) but not with EM across all subjects (Fig. $4 a, b$ ). We also performed regression analysis separately for the superior frontal and precentral cluster. The results showed that activation each in the superior frontal and precentral cluster correlated negatively with SSRT (Pearson $r=-0.592, p<0.003$ and Pearson $r=-0.646, p<$ 0.0007 , respectively). In contrast, activation in the anterior cingulate cluster did not correlate with either SSRT or EM (Fig. $4 c, d)$. Neither ROI correlated with frustration ratings.

\section{Discussion}

Successful and failed inhibitions were associated with different patterns of brain activation. These regional activations may reflect differences in attention during visual processing, signal monitoring, decision making, response execution and postresponse processing. For instance, successful inhibition was associated with greater activation in the retinotopically central visual areas, whereas failed inhibition was associated with peripheral visual areas. Previous imaging studies have shown that attention modulates visual cortical activation and allocation of attention to central vision can lead to concurrent deactivation of peripheral visual cortices (Brefczynski and DeYoe, 1999; Smith et al., 2000; Slotnick et al., 2003). The contrasting pattern of visual cortical activation may thus reflect greater attention to the visual stimuli during successful inhibitions compared with failed inhibitions. Replicating previous work, failed compared with successful inhibitions activated a medial frontal region $(x=-1, y=8, z=42$; BA 32) that has been implicated in error detection and conflict monitoring (Braver et al., 2001; Menon et al., 2001; Rubia et al., 2003, 2005; Rushworth et al., 2004). Activation in this medial frontal region may reflect greater performance monitoring after failed inhibitions. Finally, the finding of greater activation in the left motor cortex during unsuccessful inhibitions provided validating evidence for the current behavioral task, because all of our subjects responded using their right hand. Together, these findings indicated that simply contrasting successful and failed inhibitions might not be sufficient for one to isolate the neural correlates of response inhibition.

In the current study, subjects who were otherwise matched in their general performance and post-response processes were grouped into those with short and long SSRTs, to identify the neural processes involved in response inhibition. The superior and precentral frontal cortices showed greater activation during successful inhibitions even after we accounted for emotional frustration and EM. Thus, these structures mediated response inhibition independent of signal monitoring and post-response processing. Moreover, activation in these inhibitory motor areas (IMAs) correlated linearly with SSRTs, suggesting that they were directly involved in mediating response inhibition. Greater activation in the IMA leads to a shorter SSRT, which indicates more efficient stop-signal processing. Interestingly, previous studies on

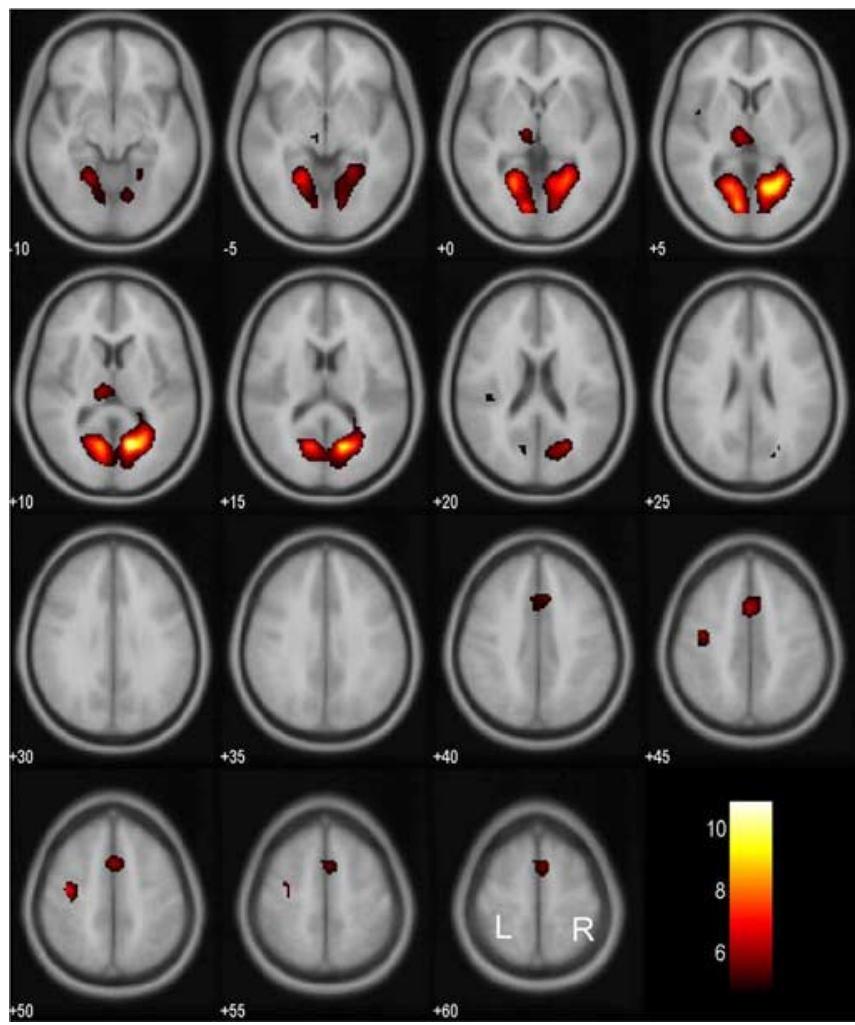

Figure 2. Brain regions showing more activation in failed compared with successful inhibitions. BOLD contrasts are superimposed on a 11 structural image in axial sections from $z=-10$ to $z=60$. The adjacent sections are $5 \mathrm{~mm}$ apart. The color bar represents voxel $T$ value. L, Left; $\mathrm{R}$, right.

Table 2. Brain regions more activated in failed compared with successful inhibitions

\begin{tabular}{|c|c|c|c|c|c|c|}
\hline \multirow{2}{*}{$\begin{array}{l}\text { Cluster size } \\
\text { (voxels) }\end{array}$} & \multirow{2}{*}{$\begin{array}{l}\text { Voxel } Z \\
\text { value }\end{array}$} & \multicolumn{3}{|c|}{ Talairach coordinates (mm) } & \multirow[b]{2}{*}{ Side } & \multirow[b]{2}{*}{ Identified region and $B A$} \\
\hline & & $x$ & $y$ & $z$ & & \\
\hline \multirow[t]{2}{*}{617} & 6.07 & 20 & -62 & 0 & $\mathrm{R}$ & Lingual G, BA 19 \\
\hline & 5.77 & -11 & -81 & -1 & $\mathrm{~L}$ & Lingual G, BA 18 \\
\hline 38 & 5.05 & -32 & -15 & 45 & $\mathrm{~L}$ & Precentral G, BA 4 \\
\hline \multirow[t]{2}{*}{91} & 4.87 & -1 & 8 & 42 & $\mathrm{~L}$ & Medial frontal G, BA 32 \\
\hline & 4.53 & 3 & 4 & 56 & $\mathrm{R}$ & Superior frontal G, BA 6 \\
\hline 53 & 4.83 & -8 & -23 & 6 & $\mathrm{~L}$ & Thalamus, pulvinar \\
\hline 3 & 4.10 & -40 & -3 & 7 & $\mathrm{~L}$ & Insula, BA 13 \\
\hline 4 & 4.02 & -36 & -30 & 16 & $\mathrm{~L}$ & Superior temporal G, BA 29 \\
\hline
\end{tabular}

Statistical threshold: $p=0.001$, FDR corrected. G, Gyrus; R, right; L, left.

epilepsy patients undergoing surgery identified two brain areas that, after electrical microstimulation, elicited inhibition of ongoing movements (Lüders, 1995). These "negative motor areas," including a medial frontal region that has been identified as a presupplementary motor area (pre-SMA) and a lateral frontal region located anterior to the face motor cortex, appeared to correspond to the IMA identified in the current study (Ikeda et al., 2000; Yazawa et al., 2000). The anterior cingulate also showed greater activation in the short compared with the long SSRT group, but only at a relaxed threshold. Activation in the anterior cingulate did not correlate with SSRT, EM effect, or frustrating rating, suggesting that this brain region probably plays a more complicated role that would require additional studies to understand (Bush et al., 2000; Rushworth et al., 2004). For instance, although the IMA is directly involved in determining motor performance, the anterior cingulate perhaps mediates higher-level and perhaps cross-model inhibitory control that does not dictate 


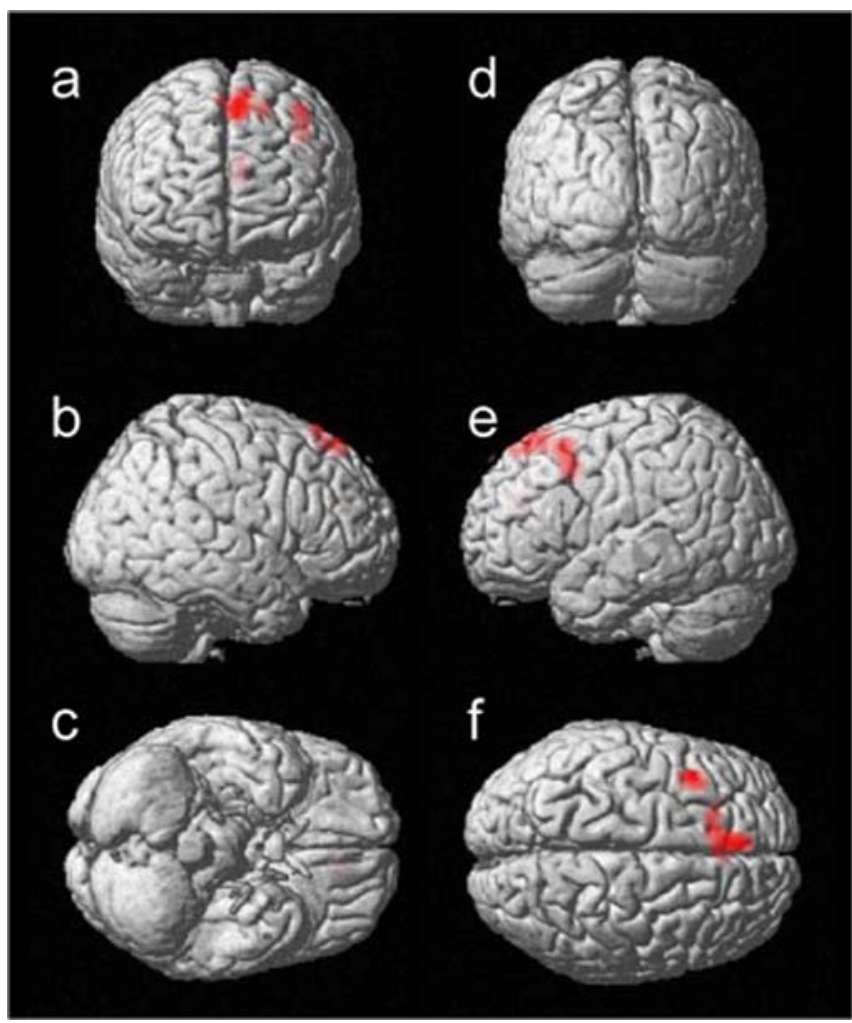

Figure 3. Brain regions showing greater activation in the short compared with long SSRT group, rendered on a single-subject three-dimensional brain. The front $(\boldsymbol{a})$, right $(\boldsymbol{b})$, bottom $(\boldsymbol{c})$, back $(\boldsymbol{d})$, left $(\boldsymbol{e})$, and top $(\boldsymbol{f})$ of the brain are shown. The results were thresholded at $p=$ 0.001 , uncorrected and 10 voxels.

Table 3. Brain regions more activated in short compared with long stop-signal processing time group

\begin{tabular}{|c|c|c|c|c|c|c|}
\hline \multirow{2}{*}{$\begin{array}{l}\text { Cluster size } \\
\text { (voxels) }\end{array}$} & \multirow{2}{*}{$\begin{array}{l}\text { Voxel Z } \\
\text { value }\end{array}$} & \multicolumn{3}{|c|}{ Talairach coordinates $(\mathrm{mm})$} & \multirow[b]{2}{*}{ Side } & \multirow[b]{2}{*}{ Identified region and BA } \\
\hline & & $x$ & $y$ & $z$ & & \\
\hline 55 & 4.91 & -4 & 32 & 51 & L & $G, B A 8$ \\
\hline 35 & 4.05 & -36 & 8 & 39 & L & Precentral G, BA 9 \\
\hline 17 & 3.46 & -8 & 35 & 19 & L & Anterior cingulate G, BA 32 \\
\hline
\end{tabular}

Statistical threshold: $p=0.001$, uncorrected; extent, 10 voxels. G, Gyrus; L, left.

moment-to-moment variation in such performance. One would thus expect the anterior cingulate cortex to participate in a wide variety of cognitive and affective tasks in which inhibitory control assumes an integral position (Schall et al., 2002; Phillips et al., 2003; Dalley et al., 2004; Isomura and Takada, 2004; Nieuwenhuis et al., 2004; Ridderinkhof et al., 2004; Ochsner and Gross, 2005).

Previous studies using the stop-signal task have identified the right IFC to be a key region in mediating response inhibition. However, the exact locale of the activated IFC area varied from one study to another (Konishi et al., 1998, 1999; Garavan et al., 1999, 2001; Rubia et al., 2001, 2003, 2005; Watanabe et al., 2002; Fassbender et al., 2004), including activation of the left IFC in some studies (Rubia et al., 2001, 2005; Durston et al., 2002; Watanabe et al., 2002; Fassbender et al., 2004). In the current study, we also observed activation of bilateral inferior and middle frontal regions when successful and failed inhibitions were contrasted, but not when the two groups with different SSRTs were contrasted. These results suggest that these middle and inferior frontal regions may differ in post-response processes between
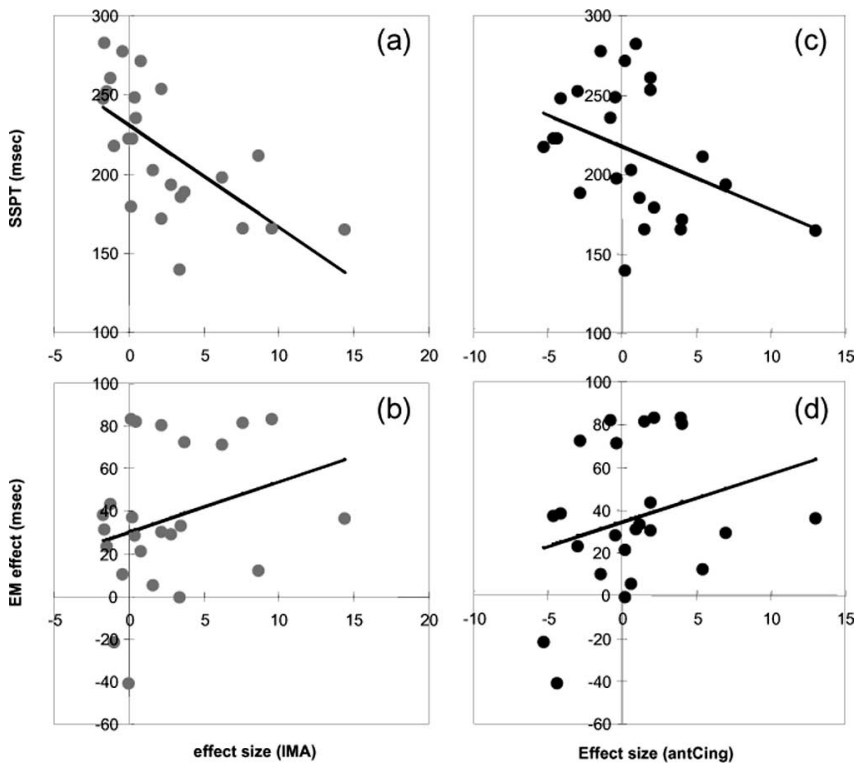

Figure 4. Activation of the IMAs demonstrated a significant negative correlation with stopsignal processing time (SSPT; $\boldsymbol{a})$, but not with EM $(\boldsymbol{b})$, across all subjects. Activation in the anterior cingulate (antCing) did not correlate with SSPT (c) or EM (d). Each data point represents one subject.

inhibition successes and failures. Indeed, the IFC has been implicated in affective processing (Fulbright et al., 2001; Nomura et al., 2003; Hennenlotter et al., 2005; Kuchinke et al., 2005; Wood et al., 2005). For instance, the IFC is part of a neural circuitry involved in perceiving and expressing pleasant facial affect (Hennenlotter et al., 2005). The middle/inferior frontal cortices have also been implicated in EM and feedback processing (O'Doherty et al., 2001; Jimura et al., 2004; Kemmotsu et al., 2005; Paulus et al., 2005). But perhaps most relevant to the current study is the hypothesis that the IFC mediates outcome monitoring of behavior (Kringelbach and Rolls, 2004). Related to this hypothesis, a recent fMRI study showed greater activation in the IFC when subjects had to select an externally guided response and monitor its outcome compared with when they selected an instructed response and had already known the outcome of their selection (Walton et al., 2004). This finding is reminiscent of signal monitoring during the stop-signal task, in which subjects prepare to make a response instructed by the go signal while monitoring for the stop signal, which essentially serves as the outcome by dictating whether a response is correct or not. With attention appropriately engaged in such monitoring processes, a subject would be more likely to succeed in withholding a response after seeing the stop signal. In contrast, one stands a greater chance of failed inhibition when responding to the go signal, assuming that no stop signal will follow (as if one has known the outcome). Greater activation of the right middle and inferior frontal cortices observed in these previous and the current studies may thus reflect greater signal monitoring during successful than failed inhibition.

Although signal monitoring can explain the activation of the IFC in these previous neuroimaging studies and the work of Aron et al. (2003) found that patients with right inferior frontal lesions were impaired in stop-signal inhibitions, a general attention mechanism could also be at play in causing inhibitory control deficits resulting from lesions in the IFC. For instance, previous animal studies showed that monkeys with lesions confined to the inferior frontal convexity perseverated in responding to a nonrewarded tone in an auditory discrimination task (Iversen and 
Mishkin, 1970, 1973). Such perseveration did not appear to result from a deficit in sensory perception, because the animals were intact at auditory sensory discrimination, or outcome monitoring, because they were not impaired in object alternation learning. These results suggest that the function of the IFC may extend beyond signal monitoring and mediate other aspects of attention function such as detection of behaviorally relevant, salient stimuli (Corbetta and Shulman, 2002; Yamasaki et al., 2002). Lesions of the IFC could thus result in indiscriminating responses to unexpected sudden onsets that mimic behavioral perseveration, as demonstrated by these monkeys in the go/nogo task (Iversen and Mishkin, 1970). These considerations perhaps also highlight the complementary roles of lesion and neuroimaging studies in elucidating regional brain functions.

Electrophysiological studies in awake monkeys and humans have long shown neural activities in the medial frontal and premotor cortices during changes in motor plans and execution of movement sequences (Amador and Fried, 2004; Leuthold and Jentzsch, 2002; Shima et al., 1996; Wise and Mauritz, 1985). These findings speak broadly to a role of the frontal cortex in the temporal organization of motor sets and inhibitions (Fuster, 2002). By controlling for general task performance and postresponse processes, the current study identified the superior medial frontal cortex as mediating response inhibition. Consistent with the current results, a previous imaging study implicated pre-SMA in mediating the motor inhibition required for voluntary muscle relaxation (Toma et al., 1999). Pre-SMA decreased activity concurrent with activation of the primary motor cortex before voluntary movements (Ball et al., 1999). Moreover, a recent study using an oculomotor paradigm found greater activation in the rostral pre-SMA in trials requiring a change in motor plan compared with those trials not requiring such a change (Nachev et al., 2005). The authors suggested that the rostral preSMA is distinctively involved in conflict control. Indeed, given the ubiquity of inhibitory control in higher cortical functions, activation of this superior medial frontal region should occur in a myriad of cognitive tasks. By constructing appropriate contrasts and ruling out cognitive and affective confounds, the current study identified a more specific role for this superior medial frontal brain area in response inhibition.

\section{References}

Amador N, Fried I (2004) Single-neuron activity in the human supplementary motor area underlying preparation for action. J Neurosurg 100:250-259.

Aron AR, Poldrack RA (2005) The cognitive neuroscience of response inhibition: relevance for genetic research in attention-deficit/hyperactivity disorder. Biol Psychiatry 57:1285-1292.

Aron AR, Fletcher PC, Bullmore ET, Sahakian BJ, Robbins TW (2003) Stopsignal inhibition disrupted by damage to right inferior frontal gyrus in humans. Nat Neurosci 6:115-116.

Ashburner J, Friston KJ (1999) Nonlinear spatial normalization using basis functions. Hum Brain Mapp 7:254-266.

Ball T, Schreiber A, Feige B, Wagner M, Lucking CH, Kristeva-Feige R (1999) The role of higher-order motor areas in voluntary movement as revealed by high-resolution EEG and fMRI. NeuroImage 10:682-694.

Braver TS, Barch DM, Gray JR, Molfese DL, Snyder A (2001) Anterior cingulate cortex and response conflict: effects of frequency, inhibition and errors. Cereb Cortex 11:825-836.

Brefczynski JA, DeYoe EA (1999) A physiological correlate of the "spotlight" of visual attention. Nat Neurosci 2:370-374.

Brett M, Johnsrude IS, Owen AM (2002a) The problem of functional localization in the human brain. Nat Rev Neurosci 3:243-249.

Brett M, Anton J-L, Valabregue R, Poline J-P (2002b) Region of interest analysis using an SPM toolbox. Paper presented at Eighth International
Conference on Functional Mapping of the Human Brain, Sendai, Japan, June.

Bush G, Luu P, Posner MI (2000) Cognitive and emotional influences in anterior cingulate cortex. Trends Cogn Sci 4:215-222.

Corbetta M, Shulman GL (2002) Control of goal-directed and stimulusdriven attention in the brain. Nat Rev Neurosci 3:201-215.

Dalley JW, Cardinal RN, Robbins TW (2004) Prefrontal executive and cognitive functions in rodents: neural and neurochemical substrates. Neurosci Biobehav Rev 28:771-784.

Durston S, Thomas KM, Worden MS, Yang Y, Casey BJ (2002) The effect of preceding context on inhibition: an event-related fMRI study. NeuroImage 16:449-453.

Friston KJ, Ashburner J, Frith CD, Polone J-B, Heather JD, Frackowiak RSJ (1995a) Spatial registration and normalization of images. Hum Brain Mapp 2:165-189.

Friston KJ, Holmes AP, Worsley KJ, Poline J-B, Frith CD, Frackowiak RSJ (1995b) Statistical parametric maps in functional imaging: a general linear approach. Hum Brain Mapp 2:189-210.

Fulbright RK, Troche CJ, Skudlarski P, Gore JC, Wexler BE (2001) Functional MR imaging of regional brain activation associated with the affective experience of pain. Am J Roentgenol 177:1205-1210.

Fuster JM (2002) Frontal lobe and cognitive development. J Neurocytol 31:373-385.

Garavan H, Ross TJ, Stein EA (1999) Right hemispheric dominance of inhibitory control: an event-related functional MRI study. Proc Natl Acad Sci USA 96:8301-8306.

Genovese CR, Lazar NA, Nichols T (2002) Thresholding of statistical maps in functional neuroimaging using the false discovery rate. NeuroImage $15: 870-878$.

Hennenlotter A, Schroeder U, Erhard P, Castrop F, Haslinger B, Stoecker D, Lange KW, Ceballos-Baumann AO (2005) A common neural basis for receptive and expressive communication of pleasant facial affect. NeuroImage 26:581-591.

Ikeda A, Ohara S, Matsumoto R, Kunieda T, Nagamine T, Miyamoto S, Kohara N, Taki W, Hashimoto N, Shibasaki H (2000) Role of primary sensorimotor cortices in generating inhibitory motor responses in humans. Brain 123:1710-1721.

Isomura Y, Takada M (2004) Neural mechanisms of versatile functions in primate anterior cingulate cortex. Rev Neurosci 15:279-291.

Iversen SD, Mishkin M (1970) Perseverative interference in monkeys following selective lesions of the inferior prefrontal convexity. Exp Brain Res 11:376-386.

Iversen SD, Mishkin M (1973) Comparison of superior temporal and inferior prefrontal lesions on auditory and non-auditory tasks in rhesus monkeys. Brain Res 55:355-367.

Jimura K, Konishi S, Miyashita Y (2004) Dissociable concurrent activity of lateral and medial frontal lobe during negative feedback processing. NeuroImage 22:1578-1586.

Kemmotsu N, Villalobos ME, Gaffrey MS, Courchesne E, Muller RA (2005) Activity and functional connectivity of inferior frontal cortex associated with response conflict. Cogn Brain Res 24:335-342.

Konishi S, Nakajima K, Uchida I, Sekihara K, Miyashita Y (1998) No-go dominant brain activity in human inferior prefrontal cortex revealed by functional magnetic resonance imaging. Eur J Neurosci 10:1209-1213.

Konishi S, Nakajima K, Uchida I, Kikyo H, Kameyama M, Miyashita Y (1999) Common inhibitory mechanism in human inferior prefrontal cortex revealed by event-related functional MRI. Brain 122:981-991.

Kringelbach ML, Rolls ET (2004) The functional neuroanatomy of the human orbitofrontal cortex: evidence from neuroimaging and neuropsychology. Prog Neurobiol 72:341-372.

Kuchinke L, Jacobs AM, Grubich C, Vo ML, Conrad M, Herrmann M (2005) Incidental effects of emotional valence in single word processing: an fMRI study. NeuroImage, in press.

Lancaster JL, Rainey LH, Summerlin JL, Freitas CS, Fox PT, Evans AE, Toga AW, Mazziotta JC (1997) Automated labeling of the human brain: a preliminary report on the development and evaluation of a forwardtransform method. Hum Brain Mapp 5:238-242.

Leuthold H, Jentzsch I (2002) Spatiotemporal source localisation reveals involvement of medial premotor areas in movement reprogramming. Exp Brain Res 144:178-188.

Levitt H (1970) Transformed up-down methods in psychoacoustics. J Acoust Soc Am 49:467-477. 
Liddle PF, Kiehl KA, Smith AM (2001) Event-related fMRI study of response inhibition. Hum Brain Mapp 12:100-109.

Logan GD (1994) On the ability to inhibit thought and action. In: Inhibitory processes in attention, memory and language (Dagenbach D, Carr TH, eds), pp 189-239. San Diego: Academic.

Lüders HO, Dinner DS, Morris HH, Wyllie E, Comair YG (1995) Cortical electrical stimulation in humans. The negative motor areas. Adv Neurol 67:115-129.

Menon V, Adleman NE, White CD, Glover GH, Reiss AL (2001) Errorrelated brain activation during a Go/NoGo response inhibition task. Hum Brain Mapp 12:131-143.

Nachev P, Rees G, Parton A, Kennard C, Husain M (2005) Volition and conflict in human medial frontal cortex. Curr Biol 15:122-128.

Nieuwenhuis S, Holroyd CB, Mol N, Coles MG (2004) Reinforcementrelated brain potentials from medial frontal cortex: origins and functional significance. Neurosci Biobehav Rev 28:441-448.

Nomura M, Iidaka T, Kakehi K, Tsukiura T, Hasegawa T, Maeda Y, Matsue Y (2003) Frontal lobe networks for effective processing of ambiguously expressed emotions in humans. Neurosci Lett 348:113-116.

Ochsner KN, Gross JJ (2005) The cognitive control of emotion. Trends Cogn Sci 9:242-249.

O’Doherty J, Kringelbach ML, Rolls ET, Hornak J, Andrews C (2001) Abstract reward and punishment representations in the human orbitofrontal cortex. Nat Neurosci 4:95-102.

Paulus MP, Feinstein JS, Leland D, Simmons AN (2005) Superior temporal gyrus and insula provide response and outcome-dependent information during assessment and action selection in a decision-making situation. NeuroImage 25:607-615.

Phillips ML, Drevets WC, Rauch SL, Lane R (2003) Neurobiology of emotion perception I: the neural basis of normal emotion perception. Biol Psychiatry 54:504-514.

Rabbit PMA (1966) Errors and error correction in choice-response tasks. J Exp Psychol 71:264-272.

Ridderinkhof KR, van den Wildenberg WP, Segalowitz SJ, Carter CS (2004) Neurocognitive mechanisms of cognitive control: the role of prefrontal cortex in action selection, response inhibition, performance monitoring, and reward-based learning. Brain Cogn 56:129-140.

Rubia K, Russell T, Overmeyer S, Brammer MJ, Bullmore ET, Sharma T, Simmons A, Williams SC, Giampietro V, Andrew CM, Taylor E (2001) Mapping motor inhibition: conjunctive brain activation across different versions of go/no-go and stop tasks. NeuroImage 13:250-261.
Rubia K, Smith AB, Brammer MJ, Taylor E (2003) Right inferior prefrontal cortex mediates response inhibition while mesial prefrontal cortex is responsible for error detection. NeuroImage 20:351-358.

Rubia K, Smith AB, Brammer MJ, Toone B, Taylor E (2005) Abnormal brain activation during inhibition and error detection in medicationnaïve adolescents with ADHD. Am J Psychiatry 162:1067-1075.

Rushworth MF, Walton ME, Kennerley SW, Bannerman DM (2004) Action sets and decisions in the medial frontal cortex. Trends Cogn Sci 8:410-417.

Schall JD, Stuphorn V, Brown JW (2002) Monitoring and control of action by the frontal lobes. Neuron 36:309-322.

Shima K, Mushiake H, Saito N, Tanji J (1996) Role for cells in the presupplementary motor area in updating motor plans. Proc Natl Acad Sci USA 93:8694-8698.

Slotnick SD, Schwarzbach J, Yantis S (2003) Attentional inhibition of visual processing in human striate and extrastriate cortex. NeuroImage 19:1602-1611.

Smith AT, Singh KD, Greenlee MW (2000) Attentional suppression of activity in the human visual cortex. NeuroReport 11:271-277.

Talairach J, Tournoux P (1998) Co-planar stereotaxic atlas of the human brain. New York: Thieme.

Toma K, Honda M, Hanakawa T, Okada T, Fukuyama H, Ikeda A, Nishizawa S, Konishi J, Shibasaki H (1999) Activities of the primary and supplementary motor areas increase in preparation and execution of voluntary muscle relaxation: an event-related fMRI study. J Neurosci 19:3527-3534.

Walton ME, Devlin JT, Rushworth MF (2004) Interactions between decision making and performance monitoring within prefrontal cortex. Nat Neurosci 7:1259-1265.

Wise SP, Mauritz K-H (1985) Set-related neuronal activity in the pre-motor cortex of rhesus monkeys: effects of changes in motor set. Proc R Soc Lond B Biol Sci 223:339-354.

Wood JN, Romero SG, Knutson KM, Grafman J (2005) Representation of attitudinal knowledge: role of prefrontal cortex, amygdala and parahippocampal gyrus. Neuropsychologia 43:249-259.

Yamasaki H, LaBar KS, McCarthy G (2002) Dissociable prefrontal brain systems for attention and emotion. Proc Natl Acad Sci USA 99:11447-11451.

Yazawa S, Ikeda A, Kunieda T, Ohara S, Mima T, Nagamine T, Taki W, Kimura J, Hori T, Shibasaki H (2000) Human presupplementary motor area is active before voluntary movement: subdural recording of Bereitschaftspotential from medial frontal cortex. Exp Brain Res 131:165-177. 